\title{
Determination of Drug Resistance and Virus Typology in HIV-1-Positive Pediatric Patients in Istanbul, Turkey
}

\author{
Özlem Yoldaşa Ali Ağaçfidan ${ }^{a}$ Nadine Lübke ${ }^{c}$ Ayper Somer ${ }^{b}$ \\ Selda Hançerlib Jens Verheyen ${ }^{c}$ Rolf Kaiser ${ }^{c}$ Baki Akgül ${ }^{c}$ \\ Departments of a Medical Microbiology and ${ }^{b}$ Pediatric Infectious Diseases, Istanbul Faculty of Medicine,

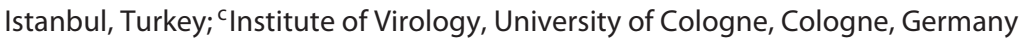

\section{Key Words}

HIV-1 · Pediatric patients · Turkey · Drug resistance

\begin{abstract}
The aim of the study was to determine the prevalence of drug resistance of HIV-1 in pediatric patients from Istanbul, Turkey. Genotypic drug resistance testing revealed transmission of drug resistance from mother to child in $20 \%$. Due to rising numbers of children with HIV-1, baseline resistance testing is recommended for Turkey.

(c) 2014 S. Karger AG, Basel
\end{abstract}

Pediatric HIV infection, which was first identified in the United States of America in 1982, has reached alarming levels with the increase in the number of HIV-positive women who are capable of childbirth. This increase happened all over the world, but mainly in sub-Saharan Africa. Children younger than 13 years of age account for $1.2 \%$ of the total number of AIDS cases reported in the United States [1]. The most important problem in the treatment and control of HIV is drug resistance, which develops over the course of treatment or is most probably transmitted by a resistant strain from a mother who re-

\section{KARGER}

E-Mail karger@karger.com

www.karger.com/int ceived insufficient antiretroviral treatment and unsuccessful prophylaxis during pregnancy. According to clinical studies, HIV infection in children can progress in two different ways. While the first type is very much similar to the one seen in adults, the second type is a fast-progressing type, which causes death in childhood with high viral loads. Considering that the immune system is weak between the ages of 0 and 3 years and only completely developed by the age of 7 years, it is clear that early diagnosis and appropriate treatment are essential [2]. Therefore, it is important that resistance tests are conducted before treatment and that the antiretroviral drugs which will give the best response to the treatment are identified. Official data of the Turkish Ministry of Health report 4,303 HIV-1 cases in Turkey registered during 19852011. With a population of more than 70 million, one might think of a low prevalence rate of HIV in Turkey. However, groups like the Positive Living Association Istanbul communicate numbers which are 10 times higher. $3.8 \%$ of the reported cases are children between the ages of 0 and 19 years [3].

The purpose of our study was to determine the frequency of HIV subtypes, drug resistance mutations of the protease and reverse transcriptase genes and gag cleavage site (CS) mutations amongst HIV-1-positive pediatric 
Table 1. Blood samples analyzed for HIV drug resistance

\begin{tabular}{|c|c|c|c|c|c|c|c|}
\hline \multirow[t]{2}{*}{ No. } & \multirow{2}{*}{$\begin{array}{l}\text { Year of } \\
\text { birth }\end{array}$} & \multirow{2}{*}{$\begin{array}{l}\text { Viral load, } \\
\text { copies/ml }\end{array}$} & \multirow[t]{2}{*}{ HIV subtype } & \multirow[t]{2}{*}{ Antiretroviral therapy } & \multicolumn{3}{|c|}{ HIV resistance mutations for } \\
\hline & & & & & NRTI & NNRTI & PI \\
\hline 2 & 2004 & 280,300 & A1 & 3TC, AZT, LPV/r & & & \\
\hline 3 & 2006 & 42,500 & $\mathrm{~B}$ & 3TC, AZT, LPV/r & M184V & & \\
\hline 4 & 2003 & 40 & $\varnothing$ & 3TC, AZT, LPV/r & & & \\
\hline 7 & 2008 & 124,159 & $\mathrm{~B}$ & 3TC, AZT, LPV/r & & & \\
\hline 8 & 2000 & 523,000 & CRF02_AG & $3 \mathrm{TC}$ & & & \\
\hline 9 & 1994 & 399,750 & $\varnothing$ & - & & & \\
\hline 10 & 2000 & 5,238 & A1 & 3TC, AZT, LPV/r, DRV & $\begin{array}{l}\text { D67N, T69NT, } \\
\text { K70R, K219Q }\end{array}$ & A98G, Y181C & $\begin{array}{l}33 \mathrm{~F}, \mathrm{I} 54 \mathrm{~V} \\
\text { V82A, L90M }\end{array}$ \\
\hline 15 & 1994 & 33,140 & $\mathrm{C}$ & - & & & \\
\hline 16 & 1994 & 7,500 & A1 & - & & & \\
\hline 17 & 1994 & 5,450 & A1 & - & & & \\
\hline 18 & 1994 & 54,890 & $\mathrm{~B}$ & - & & & \\
\hline 19 & 1995 & 25,200 & CRF02_AG & - & & & \\
\hline 20 & 1994 & 245,570 & B & - & M41L, T215S & & \\
\hline
\end{tabular}

NNRTIs = Non-nucleoside reverse transcriptase inhibitors .

patients from Istanbul, Turkey. It included 20 plasma samples of HIV-1-positive children born in Turkey, which were collected between September 2010 and May 2011. The children were aged from 0 to 18 years ( 10.9 on average) and had viral loads of 20-523,000 copies $/ \mathrm{ml}$. The common trait of the 20 pediatric patients who were receiving 2 nucleoside reverse transcriptase inhibitors (NRTIs) plus 1 protease inhibitor (PI) drug treatment was that they had been vertically infected by their mothers.

The isolation of viral RNA and genotypic resistance testing were performed as previously described $[4,5]$. Sequence analysis was successful with 15 plasma samples; in 4 samples, no HIV-1 sequences could be amplified due to low viral load ( $\leq 40$ copies $/ \mathrm{ml}$ ), most likely owing to successful therapy. One sample (No. 9) was not evaluated for HIV drug resistance due to invalid sequence data. Of the 15 sequences, 7 (46.6\%) were identified as subtype B, which is found mostly in North America, Europe and Australia. 4/15 (26.6\%) samples showed subtype A1, 2/15 (13.3\%) subtype C and another $2 / 15$ (13.3\%) the recombinant subtype variant CRF02_AG (table 1). Subtype A1 is known to be widespread in West and Central Africa, subtype C in South and East Africa, India and Nepal [6], and CRF02_AG circulates in West Africa [7].

Genotypic resistance analysis of $\mathrm{HIV}-1$ gave results in $15 / 20$ plasma samples, which were successfully sequenced. Resistance against antiretroviral drugs was found in 5/15 genotypes. Samples 1 and 3 presented the NRTI resistance mutation $\mathrm{M} 184 \mathrm{~V}$, conferring resistance to $3 \mathrm{TC} /$ FTC [8]. This mutation can be related to an early failure of the current treatment. In contrast to the genotypes of samples 1 and 3 , genotype 10 presented three-class resistance. The reported treatment history of patient 10 , included AZT, 3TC, LPV/r and DRV, and explains the NRTI and PI resistance mutations. In contrast, the detected non-nucleoside reverse transcriptase inhibitor mutations A98G and Y181C cannot be related to the reported drug treatment and may either be transmitted from mother to child or may be due to an incomplete anamnestic report before starting the current regimen. Samples 12 and 20 showed the NRTI resistance mutation M41L and the revertants T215D or T215S. Mutations at positions 41 and 215 in the reverse-transcriptase gene represent thymidine analog mutations as a result of a fail- 
ing AZT therapy and subsequent therapy interruption. Detecting such a variant indicates either a reinitiated therapy after therapy interruption or a transmitted drug resistance. The same assumption holds true for patient 20. The likelihood of a transmitted drug resistant variant is higher in this case because no previous treatment was reported for this child.

Polymorphic gag CS mutations (L449P, I437L, S451N) were frequently detected in this study. The isolate carrying PI resistance mutations (No. 10 with subtype A1) concomitantly harbored the gag CS mutation P453I, which has been associated with the presence of PI resistance mutations in subtype B isolates [9]. However, this mutation in PI-resistant subtype B isolates is quite rare since the codon usage is suggestive of a stepwise evolution at this position [WT P453 (CCA) $\geq$ P453L (CTA) $\geq$ P453I (ATA)]. Since gag CS mutation P453L occurs even more frequently than natural polymorphism in non-B subtype isolates, the gag CS P453I mutation might be more frequent as a treatment-associated gag CS mutation in nonB subtypes.
Due to the rising numbers of children infected with HIV-1 in Turkey, HIV/AIDS might develop into a priority public health concern in the coming years. In summary, we found drug resistant variants in 33\% (5/15) of the analyzed samples. Three patients displayed variants presenting resistance mutations resulting from transmission or therapy interruption. Therefore, baseline resistance testing urgently needs to be routinely performed for children in Turkey as they are not only at the start of their antiretroviral therapy but also at the beginning of their lives, which could be restricted dramatically by the wrong selection of antiretroviral drugs.

\section{Acknowledgement}

This study was supported by the Istanbul University Scientific Research Project No. 10702 and by the Bundesministerium für Bildung und Forschung (01DL12017).

\section{References}

1 Mofenson LM: Prevention in neglected subpopulations: prevention of mother-to-child transmission of HIV infection. Clin Infect Dis 2010;50(suppl 3):S130-S148.

2 Tiemessen CT, Kuhn L: Immune pathogenesis of pediatric HIV-1 infection. Curr HIV/ AIDS Rep 2006;3:13-19.

3 http://pozitifyasam.org/tr/turkiyede-hivaids.html.

4 Schülter E, Oette M, Balduin M, Reuter S, Rockstroh J, Fätkenheuer G, Esser S, Lengauer T, Agacfidan A, Pfister H, Kaiser R, Akgül B: HIV prevalence and route of transmission in Turkish immigrants living in North-Rhine Westphalia, Germany. Med Microbiol Immunol 2011;200:219-223.
-5 Alpsar D, Agacfidan A, Lubke N, Verheyen J, Eraksoy H, Cagatay A, Bozkaya E, Kaiser R, Akgul B: Molecular epidemiology of HIV in a cohort of men having sex with men from Istanbul. Med Microbiol Immunol 2013;202. 251-255.

6 Spira S, Wainberg MA, Loemba H, Turner D, Brenner BG: Impact of clade diversity on HIV-1 virulence, antiretroviral drug sensitivity and drug resistance. J Antimicrob Chemother 2003;51:229-240.

7 Hemelaar J, Gouws E, Ghys PD, Osmanov S: Global and regional distribution of HIV-1 genetic subtypes and recombinants in 2004. AIDS 2006;20:W13-W23.
8 Schuurman R, Nijhuis M, van Leeuwen R, Schipper P, de Jong D, Collis P, Danner SA, Mulder J, Loveday C, Christopherson C, et al: Rapid changes in human immunodeficiency virus type 1 RNA load and appearance of drug-resistant virus populations in persons treated with lamivudine (3TC). J Infect Dis 1995;171:1411-1419.

9 Verheyen J, Litau E, Sing T, Daumer M, Balduin M, Oette M, Fatkenheuer G, Rockstroh JK, Schuldenzucker U, Hoffmann D, Pfister H, Kaiser R: Compensatory mutations at the HIV cleavage sites p7/p1 and p1/p6-gag in therapy-naive and therapy-experienced patients. Antivir Ther 2006;11:879-887. 